\title{
Analysis characteristic of hazardous locations in urban environments
}

\author{
Željko Šarića ,' Goran Zovaka , Danijel Brkićb ${ }^{\text {, Tomislav Kučinića }}$ \\ ' Faculty of Transport and Traffic Sciences, Zagreb, Croatia \\ ${ }^{b}$ Hrvatske ceste d.o.o. Zagreb, Croatia
}

\begin{tabular}{|c|c|}
\hline ARTICLE INFO & A B S T R A C T \\
\hline $\begin{array}{l}\text { DOI: } 10.31075 / \text { PIS.66.01.06 } \\
\text { Professional paper } \\
\text { Received: } 17.01 .2020 \\
\text { Accepted: } 09.03 .2020 \\
\text { Corresponding author: } \\
\text { zeljko.saric@fpz.hr } \\
\text { Keywords: }\end{array}$ & $\begin{array}{l}\text { International experience, as well as previous research in the Republic of Croatia, } \\
\text { shows that successful identification and remediation of hazardous locations } \\
\text { results in a significant reduction in the number of traffic accidents, especially } \\
\text { those with the most severe consequences. One of the most important steps in } \\
\text { the process of identifying and remediation hazardous locations is the direct } \\
\text { inspection of the location on the ground by an expert team, which in the most }\end{array}$ \\
\hline $\begin{array}{l}\text { Traffic Accident } \\
\text { Hazardous location } \\
\text { State road } \\
\text { Urban environment }\end{array}$ & $\begin{array}{l}\text { relevant way identifies deficiencies on the road and related equipment. Total of } \\
117 \text { locations have been inspected in the Republic of Croatia in the past year, } \\
\text { which represented potentially hazardous locations on state roads, of which } 61 \text { is } \\
\text { in located in urban areas. Based on the reviews of potentially hazardous locations } \\
\text { in urban areas, significant data were collected on the condition of the road and } \\
\text { related equipment, the results of which were analysed in detail and presented in } \\
\text { this paper. Based on these results, remediation measures have also been } \\
\text { proposed, which enable increased road safety and reduced traffic accidents. }\end{array}$ \\
\hline
\end{tabular}

\section{INTRODUCTION}

The areas of the road transport network where there are a constant number of traffic accidents, in comparison with other areas of the road transport network, with human consequences or with serios material damage, are called hazardous locations. In such parts, the risk of traffic accidents is significantly increased, and such locations present some impediment to improving road motor road safety.

Therefore, it is very important to identify such locations in the road transport network in a timely manner and, with appropriate analysis and subsequent remediation, to enable smooth flow of traffic in such areas while increasing traffic safety for all users.

One of the best ways to prevent road accidents is to identify potentially hazardous locations in the road transport network and to repair them. In accordance with the new Methodology, which is in line with current legislation, guidelines and recommendations of the European Union and aims to identify the hazardous locations where the cause of traffic accidents was due to a lack of traffic and technical characteristics of the road, the company Hrvatske ceste d.o.o. in 2017, it initiated the process of identifying potentially hazardous locations on the state road network in the Republic of Croatia, identifying a total of 135 potentially hazardous locations where an average number of traffic accidents occurs. International experience shows that the most relevant results in identifying hazardous locations are achieved by reviewing such sites on the ground.

Therefore, based on the results of the identification, a process of self-examination of identified potentially dangerous sites in the field was initiated to determine whether these were indeed hazardous locations and what elements of the road infrastructure could be rehabilitated in order to increase traffic safety on the observed area of the road transport network. Of the 135 potentially hazardous locations identified, a total of 117 locations were approached on the ground.

\footnotetext{
"This paper was presented at the 7th International Conference „Towards a Humane City", 6-7th Decembar 2019. in Novi Sad, Republic of Serbia.
} 


\section{RATE QUALITY CONTROL METHOD}

The identification of potentially hazardous locations in the previous years in the Republic of Croatia, namely from 2004 to 2016, was done by a methodology that was based on a numerical definition, whereas from the beginning of 2017 a new methodology has been applied or adopted, which is based on a statistical survey of each location of traffic accidents in relation to the previous methodology, and in line with international experience and recommendations. The new methodology was used in this study to identify locations where an above-average number of traffic accidents occur over the three years 2014-2016 through the next five steps.

In the first step, at the beginning of the identification of a hazardous location, it is necessary to define on the basis of which parameters the hazardous location will be identified, or if the hazardous location are searched only on the basis of traffic accidents in which serious consequences occurred, all locations where traffic events occur should be identified on the defined network accidents with severe consequences in the last three years. In addition to the type of traffic accidents, given their consequences, it is necessary to define other characteristics of dangerous places, and this most often refers to the characteristic of the road (straight road course, bend, intersection, etc.).

In the second step of identifying a hazardous location, it is necessary to determine the method of segmenting the shares into fixed parts, which in the case of this study was a 300 meter segment within which all traffic accidents belonging to that segment were analysed, whether one or more characteristic of road network.

The third step is the statistical examination of the hazards of each location where traffic accidents occurred by default parameters, which involves defining the rate of traffic accidents. It can be defined as the ratio between the number of traffic accidents and the measure of exposure in the observation area and shows the number of accidents in relation to the traffic load on a section of road, in units:

where is:

$$
C_{R}=\frac{P N}{M}
$$

$C_{R}$ - crash rate

$P N$ - total number of traffic accidents

$M$ - average traffic volume at the site in the observed interval

The average volume of traffic over a period of one year at the observed location, which is also referred to in an international literature, and location exposure, is calculated according to the expression:

$$
M=\frac{Q \cdot 365 \cdot d}{1.000000}
$$

where is:

$Q-$ AADT (traffic demand)

$d$ - the length of the observed location

$[\mathrm{km}]$

If the rate of traffic accidents for an intersection account is then calculated using the formula of the average traffic volume in one year at the observed location:

$$
M=\frac{Q \cdot 365}{1.000000}
$$

The calculation of the critical level of occurrence of a traffic accident for each location based on the average rate of traffic accidents across all locations is characteristic of the next step of identifying a dangerous location. The critical level of traffic accidents is calculated by the expression:

$$
C_{C R}=C R_{A}+k \cdot \sqrt{\frac{C R_{A}}{M}}+\frac{1}{2 \cdot M}
$$

where is:

$C_{C R}-$ critical crash rate

$C_{R A}$ - critical crash rate average

$k$ - coefficient of confidence level (Table 1.)

Table 1. Coefficient $k$ values for different levels of significance

\begin{tabular}{|c|c|}
\hline Significance level & $\mathbf{k}$ \\
\hline $90 \%$ & 1,282 \\
\hline $95 \%$ & 1,645 \\
\hline $99 \%$ & 2,323 \\
\hline
\end{tabular}

If the rate of traffic accidents exceeds the critical level defined by this method, it is considered that traffic accidents, statistically, do not happen by accident, but are potentially hazardous. In case the traffic accident rate does not exceed the critical level, the location is not statistically potentially hazardous.

In the last part of the model, the identified potential hazardous sites are ranked according to the ratio between traffic accident rates and the critical level of traffic accidents.

\section{REVIEW OF POTENTIALLY HAZARDOUS LOCATIONS IN URBAN ENVIRONMENTS}

Analyzing the total number of traffic accidents on all state roads of the Republic of Croatia in the period 20142016 , a total of 135 potentially hazardous locations were identified, of which 117 were inspected on the ground, while five identified potentially hazardous locations were in the process reconstruction or execution of works. The seven identified potentially hazardous locations were characterized as border crossings where no analysis was possible due to the lack of detailed inspection and photographing, as well as the six identified potentially hazardous locations that were inspected as part of earlier studies of potentially hazardous sites. 
Analyzing the identified potentially hazardous locations in urban areas most commonly related to cities and populated areas, a total of 61 potentially hazardous locations $(52.00 \%)$ were identified from a total of 117 potentially hazardous locations at which a site inspection was performed. Remaining number of potentially hazardous locations inspected in the field refers to non-urban areas and a total of $56(48.00 \%)$.

Based on 61 identified, inspected and analyzed potentially hazardous locations in urban areas, as can be seen in Graph 1, it emerges that identified potentially dangerous places are located in 16 of the total 20 counties in the territory of the Republic of Croatia, since the City of Zagreb and the County of Zagreb were characterized as one county for the purposes of this study.

The largest number of identified potentially hazardous locations in urban environments is in the Primorsko goranska county ( $23.00 \%)$, followed by Ličko - senjska County $(8.00 \%)$ and Bjelovarsko - bilogorska, Brodsko - posavska, Dubrovačko - neretvanska, Splitsko dalmatinska, Šibensko - kninska and the City of Zagreb and Zagrebačka county, which identified the same number of potentially hazardous locations $(6.50 \%)$ in urban environments. A detailed account of identified, reviewed and analyzed potentially hazardous locations in urban areas by county is presented in Graph 1.

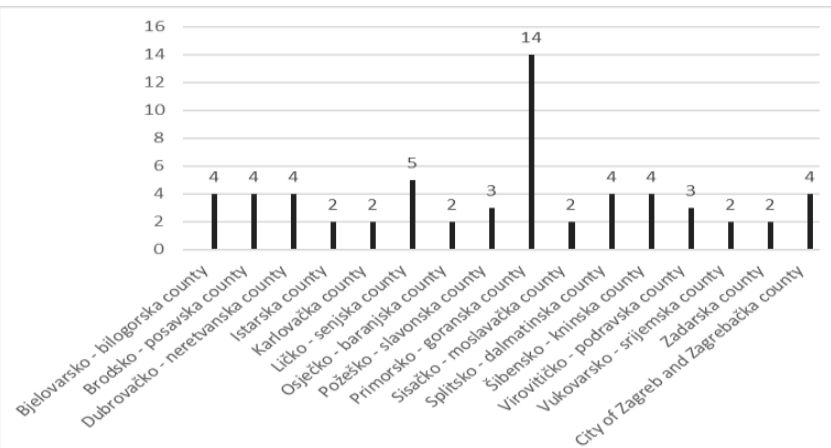

Graph 1. Detailed view of identified potentially hazardous locations in urban environments by county

The identification of potentially hazardous locations was made on the network of state roads of the Republic of Croatia, which is $7097.70 \mathrm{~km}$ long and covers a total of 190 state roads. From 61 identified, inspected and analysed potentially hazardous locations in urban areas, it is evident that identified potentially dangerous places are located on a total of 28 out of 190 national roads in the territory of the Republic of Croatia.

The largest number of identified potentially hazardous locations in urban environments is located on state road DC8 $(23.00 \%)$, which is also the longest state road with heavy traffic load throughout the year. This is followed by state road DC1 $(8.00 \%)$, state road DC2 $(6.50 \%)$, state road DC5 $(5.00 \%)$ and state road DC423 $(5.00 \%)$.

\section{Analysis of the results}

Based on the review of identified potentially hazardous locations in urban environments and the analysis of traffic and technical characteristics of the road, three categories were defined, which based on the said analysis identified the identified potentially dangerous places, each separately as:

- a hazardous location requiring measures to increase road safety,

- a location where it is justified to take measures to increase traffic safety,

- a location that does not currently require remedial action or increased traffic safety.

A total of 61 identified locations that represent a potentially hazardous locations in urban environments are divided into three categories, so a total of 15 locations $(25.00 \%)$ belong to the category of hazardous locations requiring measures to increase road traffic safety, 29 locations (47.50\%) belong to the category of locations where it is justified to take measures to increase traffic safety, while 17 locations $(27.50 \%)$ belong to the category of locations that do not currently require remediation action or increased traffic safety. If we compare the locations in urban areas with the locations of identified potentially hazardous locations in non-urban areas, we obtain a similar division into categories, so that a total of 14 locations $(25.00 \%)$ belongs to the category of hazardous location requiring measures to increase road safety, 34 locations $(60.00 \%)$ belong to the category of locations where it is justified to take measures to increase traffic safety, while 8 locations $(15.00 \%)$ belong to the category of locations that do not currently require remediation or enhancement of traffic safety

When inspecting identified locations of potentially hazardous urban locations in the field, measurements were made of the geometric elements of the road and the analysis of road equipment. The observed characteristic deficiencies for the purposes of this study are divided into 13 indicators in order to gain a better insight into the characteristics of the locations examined, which aim to identify the deficiencies of the road - technical characteristics of the road that could have led to the occurrence of the traffic accident, which are referred to in Graph 2. According to the results of the survey, 44 identified potentially hazardous locations in urban environments identified deficiencies as these sites belong to the first or second category that require or justify measures to increase road safety. The observed deficiencies of the inspected locations on the ground are not necessarily the causes of traffic accidents over the three-year period at the locations in question but are identified as defects of the road or its equipment at the specific location. Graph 3. shows the most commonly observed deficiencies at identified locations of potentially hazardous locations in urban environments. 


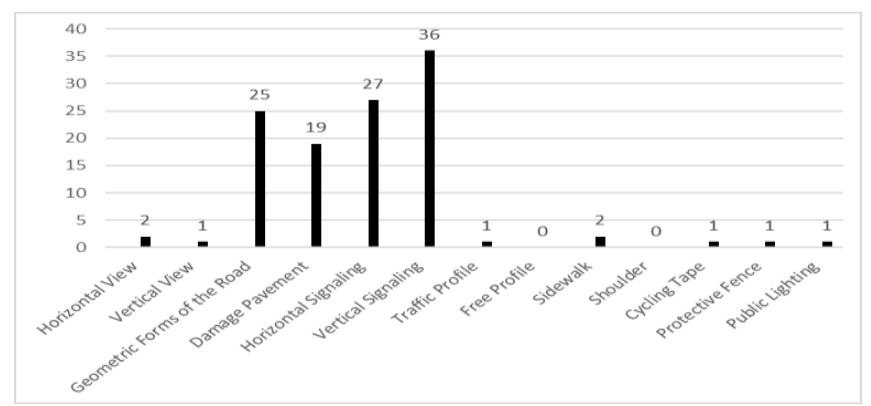

Graph 2. Deficiencies observed in roads and related equipment when inspecting identified locations of potentially hazardous locations in urban environments

Analysing the 61 inspected identified locations in urban areas where at least one defect was observed, Graph 2 , the results show that the most observed deficiencies relate to vertical signaling $(82.00 \%)$. Following in the order of the identified deficiencies are irregularities related to horizontal signaling $(61.00 \%)$, followed by geometric forms of the road $(57.00 \%)$ and pavement damage $(43.00 \%)$, which make up the set of four most commonly observed defects at the examined locations identified potentially dangerous places in urban areas.

\section{CONCLUSION}

The aim of the presented study was to identify potentially hazardous locations in the network of state roads of the Republic of Croatia on which an average number of traffic accidents occurs, and which require timely identification or remediation in order to increase road traffic safety.

Based on the new Methodology and the results of the study, which identified 135 potentially hazardous locations in the national road network in the three years 2014-2016, a process of reviewing all identified field sites was initiated, of which 117 were inspected in the field.

A field survey identified a total of 61 identified locations $(52.00 \%)$ of a potentially hazardous locations located in urban environments, most commonly referring to the center of cities traversed by the state road network in the Republic of Croatia. The remaining number of potentially hazardous locations inspected outside the urban environments are 56 (48.00\%).

Looking at counties, the largest number of identified potentially dangerous sites in urban areas is located in Primorsko - goranska county $(23.00 \%)$, then follows Ličko - senjska county (8.00\%), and Bjelovarsko bilogorska, Brodsko - posavska, Dubrovačko neretvanska, Splitsko - dalmatinska, Šibensko kninska and City of Zagreb and Zagrebačka county which identified the same number of potentially hazardous locations $(6.50 \%)$ in urban environments. If one looks at the state roads separately, the largest number of identified potentially hazardous locations in urban environments is on state road DC8 $(23.00 \%)$ which is also the longest state road with heavy traffic load all year long. This is followed by state road DC1 $(8.00 \%)$, state road DC2 $(6.50 \%)$, state road DC5 (5.00\%) and state road DC423 (5.00\%).

\section{References}

[1] Šarić, Ž., Zovak, G . (2017). Methodology for the identification of hazardous locations in the road transport network, Hrvatske ceste d.o.o., Zagreb

[2] Sørensen, M. (2007). Best Practice Guidelines on Black Spot Management and Safety Analysis of Road Networks, Institute of transport economics report 898/2007, Oslo, Norway

[3] Elvik, R. (2007). State-of-the-art approaches to road accident black spot management and safety analysis of road networks, Institute of transport economics report 883/2007, Oslo, Norway

[4] Sørensen, M., Elvik, R. (2007). Black Spot Management and Safety Analysis of Road Networks - Best Practice Guidelines and Implementation Steps, Institute of transport economics report 919/2007, Oslo, Norway

[5] Cardoso, J., Stefan, C., Elvik, R., Sorensen, M. (2008). Road Safety Inspections: Best practice and implementation plan, Deliverable D5 of the RIPCORD-iSEREST project- European commission 